\title{
THEORY AND PRACTICE PROFESSIONAL DEFORMATION OF MILITARY PERSONNEL
}

\author{
Ruzmet Muratovich Makhmudov \\ Professor at the department \\ "Psychology and Pedagogy" of \\ Military-Technical Institute of National Guard \\ of the Republic of Uzbekistan, \\ Doctor of Sciences in Pedagogy, \\ Tashkent, Republic of Uzbekistan
}

\author{
Gayrat Zokirovich Ikmatullaev \\ Assistant-Professor at the Department \\ "Psychology and Pedagogy" of \\ Military-Technical Institute of National Guard \\ of The Republic of Uzbekistan, \\ Doctor of Philosophy (PhD) in Pedagogy, \\ Tashkent, Republic of Uzbekistan
}

\author{
Azizbek Adashboy ugli Ernazarov \\ Teacher at the department of \\ "General military sciences" of \\ Military-Technical Institute of National Guard \\ of The Republic of Uzbekistan, \\ Senior lieutenant, Tashkent, \\ Republic of Uzbekistan
}

Article DOI: https://doi.org/10.36713/epra5641

\begin{abstract}
This article discusses the concept of professional deformation of military personnel and its theoretical and practical aspects. The peculiarities of the occurrence of occupational deformity have been scientifically substantiated.

KEY WORDS: Military service, competence, professional deformation, mental disorder, deviant behavior, individual character, mental relief.
\end{abstract}

\section{INTRODUCTION}

It is clear that every professional will experience professional deformation after a certain period of time. Occupational deformation is a broad concept and depends in many ways on the content of the profession. Elements of professional misconduct are manifested primarily in the behavior of military personnel, in the negative nature of service. Occupational impairment (deformation) is a reflection of professional competence. For military personnel, professional misconduct is a negative process that should and should not happen. The basis of an occupational disorder is a mental disorder, whereas a mental disorder is directly related to deviant (deviant) behavior. When we think of a professional disorder, we definitely define that concept. Thus, professional misconduct is a negative impact on the psyche and activities of a serviceman as a result of his long service in a profession. Several scholars have attempted to study the psychological, pedagogical, and legal aspects of this problem [1, p.23]. The pedagogical aspects of professional deformation have been partially overlooked by scholars in the field of legal pedagogy. Without studying the theory of professional deformation, we cannot fully study its practical aspects there is not enough basis to reveal its essence.

\section{METHODS}

A military serviceman is a stress-rich profession just like a police officer. Military personnel (more often referred to as National Guard personnel) also have a negative outlook on society, are reluctant to work, prone to theft, quarrels, and, if necessary, professional misconduct as a result of working directly with not only offenders but also murderers. Citizens may not invite law enforcement officers, National Guard servicemen to a wedding. 
However, they will definitely be contacted for lifestyle issues related to the service.

\section{RESULTS AND DISCUSSIONS}

The first sign of professional deformation is, first of all, in the attitude of servicemen to the profession, duty, "late service, late performance, high self-esteem, abuse of office, disrespect for citizens", on the other hand, the fate of citizens who apply indifference, failure to consider the application in a timely manner, incompetence, etc. All of these signs listed above are actions that discredit all military personnel. Professional deformation as a problem began to be studied by scientists from the middle of the XX century [2, p.272]. The geography of military personnel deformation is wide, and such deformation not only affects their service activities, but also their family members. Negativeness in the family also has an impact on the positive development of the family as a part of society, as a social institution. It is no secret that the professional deformation of the head of the family is not limited to the mental changes in him, but also affects the psyche of his colleagues. Children, the role of the mother in the prevention of socio-psychological factors in the family of servicemen is great. Because the joy of the child is the joy of the parents, they both turn their fatigue, changes in mood to the positive. We found out during our direct interviews with the military that more professional deformation can also be caused by the wrong choice of profession. The manifestation of occupational deformation is also related to the nature of the profession. For example, it is natural for a teacher to teach more people and always talk a lot, trying to explain something. In tractor drivers, on the other hand, the tractor can fall asleep inside even if it is on fire, and can continue to sleep for hours. He wakes up when the tractor turns off. Soldiers who serve with weapons will no longer be afraid of the sound of bullets. Doctors try to find some disease in the patient. When you walk into a shoe repair shop, they look at your shoes. Disbelief and suspicion are predominant in law enforcement officers [3]. The theoretical and psychological aspects of occupational deformation have been studied in more detail by the following scholars (on the example of law enforcement officers). For example, A.R.Ratinov, G.G.Shixantsov, N.L.Granat, A.I.Papkin, K.R.Takasaeva, A.V.Budanova tried to create a psychological portrait of the employee through professional deformation. B.S. Medvedov focused on the professional deformation of the criminal investigation officer. Professional deformation begins to occur over the years in service. During the 11 to 15 years of service, all elements of professional deformation will be formed and developed. The deformation will culminate during the service life of 20 years or more. The culmination is what actions we can see in employees. For instance, they wear the clothes of their service days, that is, their shoes or shirts, their boots, their field clothes (we get the answer that they are accustomed to the question, "Why are you wearing clothes?". That they are comfortable and do not want to leave). In addition, slang words are used by military personnel both on the street and in the family. It will be difficult for them to get rid of these words. In addition, many servicemen try to find work in their profession after retirement. Jobs aren't always found, and as a result, security guards get hired.

It is natural that the occurrence of occupational deformation is primarily caused by occupational stress. A military serviceman may accumulate negative qualities, including fatigue. The most horrible aspect of professional deformation is that it changes the individual character in the professional. This negative trait becomes episodic, persistently superficial in the military. Preventive measures will need to be taken to prevent the impact of deformities on occupational activities in military personnel and personnel, especially the provision of opportunities for rest. That is, psychological relief is a must for every serviceman. The answer to the question of who organizes psychological relief is psychological centers. But military personnel do not have time to enter these places.

\section{CONCLUSION}

In conclusion, it should be noted that professional deformity was found to be overt and covert during our observation. In the first case, the military is indifferent to the fate of civilians, while in the other, it is manifested in the abuse of office. Abuse must be understood in a broad sense. At this point, analyzing the specific literature, we came to the following conclusion. That is professional deformation is a process aimed at changing the military character of the profession, an increase in professional experience is the basis for the occurrence of professional deformation.

\section{REFERENCES}

1. Rozhkov O.A. Motivational determinants of professional deformation of the personality of employees of the penal system: Abstract dissertation for the degree candidate psychology sciences. -Ryazan, 2013.-23 p.

2. Krasinskaya E. S. Professional deformation of the personality of an employee of the internal affairs bodies and its prevention // Bulletin of the East Siberian Institute of the Ministry of Internal Affairs of Russia.№.3 (78) 2016.-p.48-52.

3. Bisengulova A.R., Nosova D.Kh. Professional deformation of police officers and ways to prevent it. B.G.P.U. -Ufa. 2016. p.159-163.

4. Davletbaeva Z.K., Faizullina L.R. E - mail: dav zinfira@yandex.ru: S.P. Beznosov Professional personality deformation. SPZ. 2004. 272 p. 